\title{
Emergency obstetrics knowledge and practical skills retention among hospital and clinic staff following advanced life support obstetrical training in Cameroon, Africa
}

\author{
Ngoran Grace Bongban, Dorothy J. Meyer, Peter M. Gatongi, Mbai I. Isabella \\ Moi University, Eldoret, Kenya
}

\begin{abstract}
Background: Although worldwide rates have decreased, maternal mortality remains a major public health challenge in many resource limited countries. In 2015, Cameroon had the 10th highest maternal mortality rate ranking in the world. The "three delays" model identifies common barriers to accessing emergency obstetrical care (EmOC): 1. a delay in the decision to seek emergency care; 2. a delay in reaching emergency care; and, 3. a delay in being providing safe and adequate emergency care in the health facility. This study addresses the 3rd delay: providing safe and appropriate EmOC in the health care facility.

Method: The Advanced Life Support in Obstetrics (ALSO) is an internationally recognized course which provides training for health care workers (HCW) to manage emergency obstetrical conditions. The ALSO course was made available by the Cameroon Baptist Convention Health Services to any health care facility who wished to send their HCW's for emergency obstetrical training. This study investigates the retention of knowledge and skills among these HCW's, 6-31 months, after completing the course.

Results: From May 2012 to December 2014, 156 HCW's completed the ALSO training course with 99 (64.5\%) participating in this knowledge and skill retention study. The HCW's perceived the training to be beneficial (95.9\%) and identified utilizing some of the skills taught (90.8\%). The skill maintenance was measured by the HCW's ability to pass the ALSO practical skill retest. The HCW skill pass rate decreased from $65.4 \%$ at the initial training to $34.6 \%$ on retest (P=0.006). Skill maintenance was associated with individual motivation, and the HCW's ability to use the skills in their work environment. There was no association with time since the training course and skill maintenance. The primary predictor of failing the retest was a failing score on the initial testing.
\end{abstract}

Conclusion: This study showed that ongoing "refresher courses" and the ability to practice skills are required to maintain the quality of EmOC. Facilities should be evaluated to identify the appropriate level of emergency care with the EmOC training tailored to meet the staff and facilities capacity.

\begin{abstract}
Abbreviations: MDG: Millennium Development Goals; MMR: Maternal Mortality Rate; EmOC: Emergency Obstetric Care; SSA: sub-Saharan Africa; CBCHS: Cameroon Baptist Heath Service; ALSO: Advanced Life Support in Obstetrics; AAFP: American Academy of Family Practice; BLSO: Basic Life Support in Obstetrics; C-BLSO: Community Basic Life Support in Obstetrics; PPH: Post-Partum Haemorrhage; IHC: Integrated Health Centre; MgSO4: Magnesium Sulfate; HCW: Health Care Workers
\end{abstract}

\section{Introduction}

In 2000, eight Millennium Development Goals (MDGs) were established by the United Nations. The fifth MDG was to decrease maternal mortality (WHO defines a maternal death as "the death of a woman while pregnant or within 42 days of termination of pregnancy, irrespective of the duration and site of the pregnancy, from any cause related to or aggravated by the pregnancy or its management but not from accidental or incidental causes") by 75\% between 1990 and 2015 . To date, worldwide maternal deaths have dropped by $45 \%$. Presently, almost all maternal deaths (99\%) take place in resource limited countries with more than one-half of these deaths occurring within sub-Saharan Africa [1].
A recent WHO systematic analysis of the causes of 60,799 maternal deaths, between 2003 and 2009, found that almost $73 \%$ of maternal deaths were due to obstetrical causes with $27.5 \%$ secondary to indirect causes [2]. Direct obstetrical causes of deaths included haemorrhage, hypertensive disorders, sepsis, abortion, embolism, and other obstetrical complications including obstructed labour. Over onehalf of these obstetrical deaths were due to hemorrhage, hypertensive disorders, and sepsis which occurred during labor and delivery and post-delivery. However, more than a quarter of all maternal deaths were due to pre-existing conditions aggravated by the pregnancy, including HIV/AIDS, malaria, hypertension, diabetes, and obesity. This study exhibits the continued burden of infectious diseases, as well as the growing impact of non-communicable diseases upon women's

Correspondence to: Dorothy J. Meyer, 7409 Bullion Hill Road, Flagstaff, Arizona, 86045, USA, Tel: + 1928526 5419; E-mail: DotJMeyer@aol.com

Key words: maternal mortality, advanced life support in obstetrics, emergency obstetrical care, knowledge and skill retention, third delay, Cameroon

Received: February 19, 2016; Accepted: April 08, 2016; Published: April 11, 2016 
health.

The global Maternal Mortality Ratio (MMR) has decreased from 380 deaths/100,000 live births (1990) to 210 deaths/100,000 live births [3]. Yet, the MMR remains the highest in sub-Saharan Africa (SSA) at 510 deaths $/ 100,000$ live births [3]. If present trends continue, it is anticipated that SSA will reach a MMR of 128-357/100,000 live births in 2030, which is more than double the time in other world regions [4].

Multiple strategies are required to reduce the maternal mortality. One of these strategies is to make Emergency Obstetric Care (EmOC) acceptable, accessible, and available to women and their families. Three barriers to obtaining EmOC have been described [5-10] including:

1. A delay in the decision to seek maternity care: the woman and family delay accessing obstetrical care secondary to financial constraints, poor understanding of pregnancy complications, and community/cultural beliefs which may reinforce delays or promote alternate treatments.

2. A delay in reaching maternity care: no available or accessible transportation, poor roads, and geography.

3. A delay in receiving adequate maternity care: inadequate facilities, lack of medical equipment and supplies, poor referral systems, and inadequately trained, skilled and motivated medical and nursing staffs.

WHO estimates that $50-70 \%$ of maternal deaths could be prevented with access to good obstetrical emergency care [11]. This study focuses upon the $3^{\text {rd }}$ delay: receiving adequate EmOC at the health care facility.

\section{Background}

In Cameroon, recent data indicates that the MMR has increased from 430 deaths/100,000 live births (1998) to 782/100,000 live births (2011) with an estimated 5,000 to 7,000 pregnant women dying every year [12]. Therefore, as of 2015, Cameroon has exhibited no progress toward meeting the $5^{\text {th }}$ MDG. Additionally, this rate places Cameroon as the nation having the $10^{\text {th }}$ highest MMR ranking in the world [13]. In May 2014, the Cameroon Government launched a "Multisectoral Programme to Reduce Maternal and Child Mortality (2014-2018)" [13]. This programme is coordinated by the Ministry of Health and includes a wide range of government, civil organizations, and private sector stakeholders, with the program goal to decrease the MMR by $25 \%$ within 5 years. In Cameroon, gaps in obstetrical services have been identified, including limited EmOC services which are often of inadequate quality [14]. To date, concerns continue that many public and private health care facilities lack adequately trained staff with limited accessibility to and availability of the equipment and supplies required for EmOC [15].

In an effort to improve the quality of maternity care, the Cameroon Baptist Convention Health Services (CBCHS) introduced the Advanced Life Support in Obstetrics (ALSO) Training Course as an ongoing obstetrical staff educational effort. The ALSO Program is an "evidence-based, hands-on clinical content, team work, patient safety and treating obstetrical emergencies, for maternity care providers, including physicians, nurse midwives and registered nurses" [16]. There is a second course, the Basic Life Support in Obstetrics (BLSO) which is a training to "manage normal labor and Perinatal emergencies for pre-hospital teams" [16]. In 1991, the ALSO program was developed in the United States by University of Wisconsin physicians to provide medical and nursing staffs the knowledge and skills to manage urgent and emergency obstetrical conditions. In 1993, the responsibility for
ALSO training was assumed by the American Academy of Family Physicians (AAFP). ALSO training was so successful that it has been expanded internationally, with modifications made to meet the relevant needs and resources of developing countries $[17,18]$. In an effort to bring lifesaving skills to a broader audience of health care workers (HCW), the BLSO has been further modified as the Community-Based Life Support in Obstetrics (C-BLSO). The C-BLSO training focuses upon low tech solutions to the most common obstetrical emergencies and can be used to train skilled birth attendants, community nurses, nursing assistants, birth attendants, and community members who attend deliveries in resource challenged settings [19].

The CBCHS is a private, faith-based health care system consisting of six hospitals, 29 health centres, and 50 primary health centres, almost all of which provide maternity care. In 2014, the CBCHS obstetrical care workload included 9876 live births, 271 preterm births, 41 neonatal deaths, 80 babies born before arrival to the facility, 183 still births, and 171 abortions [20].

With the concurrence and approval of the Cameroon Regional Delegates for Health, the ALSO Training Course was initiated by the CBCHS within the Northwest and Southwest regions of Cameroon. The CBCHS, government, and private facilities were invited to send staff to an ALSO training session. Multiple trainings were scheduled with participants limited to 5 per each instructor (ALSO criteria). No course or registration fee was requested, with the required teaching tools, including mannequins, equipment, supplies, and manuals, provided through private donations. The participants' sponsoring institutions were responsible for funding the cost of travel, lodging, and food. ALSO Approved Instructors from the US and Kenya taught the initial training course.

The AAFP ALSO training includes the administration of a standardized written test and practical testing exercise at course completion. Upon passing this testing, an ALSO Provider status is awarded and valid for 5 years. Current ALSO Providers are qualified to attend an ALSO Instructor course enabling them to become an ALSO Approved Instructor.

In Cameroon, an ALSO instructor course ("Train the Trainers") was held immediately following the initial ALSO training with continued instructor courses offered at intervals. Those ALSO Providers with teaching capabilities are encouraged to consider becoming ALSO instructors. This process has enabled a cadre of local staff to qualify as instructors and provide ongoing ALSO training which assures program sustainability

Studies have raised concerns about the retention of knowledge and skills after completing emergency medical training, as well as the need for refresher courses [21-24]. This study was performed to identify the retention of emergency obstetrical knowledge and skills, 6-31 months, after completing an ALSO course.

\section{Objectives}

The study objectives were to:

1. Evaluate the self perception of knowledge and skill retention of ALSO trainees 6 to 31 months following completion of the course.

2. Identify factors which may influence the participant's knowledge and skill retention following emergency obstetrical training.

3. Determine the relationship of participant's self-confidence and demonstrable skills in managing obstetrical emergencies. 
The CBCHS Institutional Review Board granted approval for this study and gave permission for publication of the findings. In addition, approval was granted by the Institutional Research and Ethical Committee of Moi University, Kenya. Finally, the study received approval from the CBCHS Director.

\section{Methods}

This study consisted of:

- A comparison of the participant's initial ALSO practical skills testing results to repeat (study) ALSO practical skills testing results,

- Administration of the ALSO questionnaire with modifications to include the participant's self-assessment of their confidence of managing obstetrical emergencies, and

- Completion of a checklist of ALSO recommended equipment and supplies to identify availability within their facility.

The ALSO tests and equipment check lists are standardized tools with proven validity and reliability. The ALSO questionnaire was modified to meet the additional needs of this study. The continued validity of the modified questionnaire was ascertained by having international experts review the additions with their suggestions incorporated into the questionnaire. The questionnaire was then pilot tested by 10 individuals who had completed the ALSO training within 6 months of the scheduled study testing. Based upon their responses, some minor modifications were made to the questionnaire.

The primary author and the Programme Manager first administered the ALSO practical skill tests to 9 volunteer ALSO Instructors. Upon completion of the repeat testing, these instructors then received training which enabled them to serve as research assistants and administer the questionnaire and practical skills test to the other study participants.

An invitation letter from the CBCHS Director was sent to all ALSO trainees eligible to participate in the study. This letter included information concerning the study, the study consent form, and the equipment check list. Central locations were identified which would facilitate participation with transportation provided to the most accessible study location.

All volunteers were asked to sign a written consent prior to study participation. Anonymity was assured with each participant being assigned a special code which was securely maintained with access only by the primary investigator. Data were entered into Microsoft Excel and Epi-Info (Centers for Disease Control and Prevention) software for analysis. Study participants could select to answer or not answer any question and to complete the equipment listing as they wished.

The primary author attempted to reach non-responsive ALSO trainees by telephone to personally invite them to participate in the study. Fifty seven (36.5\%) trainees did not participate for a number of reasons, including being out of country, in school, on leave, having difficult personal circumstances, or having no phone contact. Only three eligible trainees declined to participate.

Every effort was made to perform an accurate and objective evaluation of each participant's practical skill retest. This consisted of the primary author and research assistants observing the participants skill test, reviewing the performance of each participant, discussing their findings, and coming to a consensus as to the correct skill rating of each participant.

From May 2012 to December 2014, 156 HCW's completed an
ALSO training course with 22 of the attendees becoming ALSO instructors, including the primary author. In 2015, 99 ALSO trainees (63.5\%) voluntarily participated in this study, which included 15 ALSO instructors.

\section{Results}

\section{Study participant's demographics and work characteristics}

Table 1 presents the study participants demographics and work characteristics. More participants were over 40 years of age $(60.6 \%)$ with an average age of 41 years (range 26-60 years). Almost $60 \%$ of participants had 1-10 years of experience with an average work experience of 10.5 years (range 1 to 41 years). Ninety-three (93.9\%) participants met the WHO criteria of a Skilled Birth Attendant with $46.4 \%$ being trained midwives. Most participants (73.7\%) were actively providing maternity care. Over half $(51.5 \%)$ of the study participants worked in hospitals, with all but 3 hospitals having C-Section capability. The participants included 78 (78.8\%) CBCHS staff, 13 (13.1\%) government staff, and 7 (7.1\%) private facility staff.

Table 1. Participant's demographics and work characteristics.

\begin{tabular}{|c|c|c|}
\hline \multicolumn{3}{|c|}{ ALSO practical skills retention participants demographics \& work characteristics } \\
\hline & Number & Percent \\
\hline \multicolumn{3}{|l|}{ Gender } \\
\hline Male & 33 & $33.3 \%$ \\
\hline Female & 66 & $66.7 \%$ \\
\hline Total & 99 & \\
\hline \multicolumn{3}{|l|}{ Age } \\
\hline $26-29$ & 4 & $4.0 \%$ \\
\hline $30-39$ & 33 & $33.3 \%$ \\
\hline $40-49$ & 49 & $49.5 \%$ \\
\hline $50-60$ & 11 & $11.1 \%$ \\
\hline Not Identified & 2 & $2.0 \%$ \\
\hline Total & 99 & \\
\hline \multicolumn{3}{|l|}{ Profession } \\
\hline Trained Midwife & 46 & $46.5 \%$ \\
\hline Nursing Assistant With Ob Training & 30 & $30.3 \%$ \\
\hline Registered Nurse & 11 & $11.1 \%$ \\
\hline Md-General Practitioner & 6 & $6.1 \%$ \\
\hline Nursing Assistant & 5 & $5.1 \%$ \\
\hline Other & 1 & $1.0 \%$ \\
\hline Total & 99 & \\
\hline \multicolumn{3}{|l|}{ Years of Experience } \\
\hline 1 to 10 years & 58 & $58.6 \%$ \\
\hline 11 to 20 years & 32 & $32.3 \%$ \\
\hline 21 to 30 years & 6 & $6.1 \%$ \\
\hline 31 and more years & 3 & $3.0 \%$ \\
\hline TOTAL & 99 & \\
\hline \multicolumn{3}{|l|}{ Working in Maternity Care } \\
\hline Yes & 73 & $73.7 \%$ \\
\hline N0 & 26 & $26.3 \%$ \\
\hline Total & 99 & \\
\hline \multicolumn{3}{|l|}{ Work Place } \\
\hline Hospital & 51 & $51.5 \%$ \\
\hline Integrated Health Center & 45 & $45.5 \%$ \\
\hline Other & 3 & $3.0 \%$ \\
\hline Total & 99 & \\
\hline \multicolumn{3}{|l|}{ Work Site } \\
\hline Urban & 71 & $71.7 \%$ \\
\hline Rural & 28 & $28.3 \%$ \\
\hline Total & 99 & \\
\hline
\end{tabular}




\section{Study participant's perception of ALSO training}

The ALSO training was perceived by the participants to be beneficial with $94(95.9 \%)$ saying the training increased their knowledge, and $89(90.8 \%)$ saying they had used one of more of the emergency skills learned since their training. Most participants expressed confidence in their ability to manage the 9 complications $(70.1 \%-90.7 \%)$ and 3 procedures (63.8\%-84.2) which are addressed within the course (Table 2).

However, when matched to the retest skill scores, fewer participants ( $44 \%$ to $50 \%$ ) were able to demonstrate adequate practical skills to manage the complications and procedures by passing the retest.

In response to questions regarding specific complications, the study participant's identified Post-Partum Haemorrhage (PPH) and Shoulder Dystocia as the most common obstetrical emergencies managed in their clinical practice. Eighty $(80.8 \%)$ participants thought that their management of $\mathrm{PPH}$ had improved since the ALSO training with $77.1 \%$ estimating a decrease in patient blood loss after the training. During the past year, 77 (77.8\%) participants said they had managed at least one patient with $\mathrm{PPH}$, with the 3 most identified interventions being fundal massage (Number=64; 83.1\%), IV fluids (Number=63; $81.8 \%$ ), and cytotec administration (Number $=56 ; 72.7 \%$ ).

During the past year, 55 (55.6\%) participants identified they had encountered a Shoulder Dystocia during at least one delivery (1 to "many times") with 44 (44.4\%) participants saying they had never seen a Shoulder Dystocia. The 3 most common maneuvers used to deliver these patients were McRoberts maneuver (Number=42;76.4\%), suprapubic pressure (Number $=31 ; 56.4 \%)$, and turning the patient to their hands/knees for delivery (Number $=22 ; 40.0 \%$ ). Thirty-six of the participants, who delivered patients identified to have Shoulder Dystocia, worked in hospitals while 15 worked in Health Centre's.

Three procedures are taught which are used in obstetrical emergency care: vacuum-assisted deliveries, maternal resuscitation, and neonatal resuscitation. The percent of retest participants who identified confidence in performing these procedures were: vacuum delivery $(63.8 \%)$, maternal resuscitation $(77.7 \%)$, and neonatal resuscitation $(84.2 \%)$. Of the participants, who identified their skill confidence, $43.8 \%-45.2 \%$ passed the skill retest.

In the past year, 66 (66.7\%) study participants said they had not

Table 2. Self-identified confidence in managing obstetrical emergencies and retest skill scores.

\begin{tabular}{|c|c|c|c|}
\hline \multicolumn{4}{|c|}{$\begin{array}{l}\text { Participants self-assessment of comfort in managing pregnancy complications } \\
\text { and retest score }\end{array}$} \\
\hline & & Percent & Percent \\
\hline Complication of Pregnancy & $\begin{array}{l}\text { Comfortable } \\
\text { with Care }\end{array}$ & $\begin{array}{l}\text { Comfortable } \\
\text { with Care }\end{array}$ & $\begin{array}{l}\text { Comfortable } \\
\& \text { Retest Pass }\end{array}$ \\
\hline Postpartum Hemorrhage $(\mathrm{n}=97)$ & 88 & $90.7 \%$ & $37.5 \%$ \\
\hline Multiple Fetuses $(\mathrm{n}=98)$ & 83 & $84.7 \%$ & $44.6 \%$ \\
\hline Third Trimester Bleeding $(\mathrm{n}=96)$ & 75 & $78.1 \%$ & $49.3 \%$ \\
\hline First Trimester Bleeding $(\mathrm{n}=95)$ & 75 & $78.9 \%$ & $48.0 \%$ \\
\hline Preeclampsia/Eclampsia $(n=96)$ & 73 & $76.0 \%$ & $50.7 \%$ \\
\hline Shoulder Dystocia $(\mathrm{n}=96)$ & 73 & $76.0 \%$ & $50.7 \%$ \\
\hline Preterm Labor \& PROM (n=93) & 73 & $78.5 \%$ & $50.7 \%$ \\
\hline Labor Dystocia $(\mathrm{n}=96)$ & 71 & $74.0 \%$ & $47.9 \%$ \\
\hline Malpresentation $(\mathrm{n}=97)$ & 68 & $70.1 \%$ & $50.0 \%$ \\
\hline \multicolumn{4}{|l|}{ Procedures } \\
\hline Vacuum Delivery $(\mathrm{n}=94)$ & 60 & $63.8 \%$ & $53.3 \%$ \\
\hline Maternal Resuscitation $(\mathrm{n}=94)$ & 73 & $77.7 \%$ & $45.2 \%$ \\
\hline Neonatal Resuscitation $(\mathrm{n}=95)$ & 80 & $84.2 \%$ & $43.8 \%$ \\
\hline
\end{tabular}

performed a vacuum-assisted delivery, with 33 participants performing 1-15 vacuum extractions. Twenty-seven of the participants performing vacuum extractions worked in hospitals with 6 working in health centres. All participants performing 6 or more vacuum-assisted deliveries worked within hospitals. Complications encountered by participants at vacuum assisted deliveries included: cephalhematoma (33.3\%), infant bruising (4.2\%), vaginal lacerations (66.7\%), excessive blood loss (16.7\%).

\section{Study participant's initial and repeat pass/fail score results}

By ALSO criterion, a test score of 70 and more is considered a passing score. Sixty-five (65.6\%) study participants passed their initial practical training test with $34(34.4 \%)$ failing (mean score $=72.9$, range 12-97). Forty (40.4\%) passed the study practical retest with 59 (58.6\%) failing (mean test score $=55.6$, range $0-98$ ). The decrease in the pass rate from the initial ALSO training to the retest was statistically significant $(\mathrm{P}=0.006)$. Of the 65 study participants who passed the initial ALSO Training, 35 (53.9\%) passed the retest and 30 (46.1\%) failed the re-test. Eighteen of the 35 participants who passed the retest increased their score while the remaining 17 had decreased (yet passing) scores. Of the 34 study participants who failed the initial training, 21 (61.8\%) also failed the retest with a decreased score; 13 participants increased their failing score with 5 achieving a passing score.

Table 3 presents the initial ALSO practical training PASS Rates compared to the retest PASS Rates by work characteristic. There was a decrease in PASS rates in all categories with the p-values of statistically

Table 3. PASS Rates Comparison by Work Categories.

\begin{tabular}{|c|c|c|c|c|c|c|}
\hline \multicolumn{7}{|c|}{ ALSO practical skills retention initial and retest scores of practical skill evaluation } \\
\hline & \multirow{3}{*}{$\begin{array}{c}\text { Group } \\
\text { Total }\end{array}$} & \multirow{2}{*}{\multicolumn{2}{|c|}{\begin{tabular}{|c|} 
Initial Evaluation \\
Total
\end{tabular}}} & \multirow{2}{*}{\multicolumn{3}{|c|}{$\begin{array}{r}\text { Retest Evaluation } \\
\text { Total }\end{array}$}} \\
\hline & & & & & & \\
\hline & & Passing & Pass rate & Passing & Pass rate & P-value \\
\hline \multicolumn{7}{|l|}{ Cadre of Worker } \\
\hline Physician & 6 & 6 & $100.0 \%$ & 4 & $66.7 \%$ & \\
\hline Trained Midwife & 46 & 32 & $69.6 \%$ & 19 & $41.3 \%$ & $0.015^{*}$ \\
\hline $\begin{array}{l}\text { Nursing Assistant with } \\
\text { OB Training }\end{array}$ & 30 & 21 & $70.0 \%$ & 12 & $40.0 \%$ & $0.037^{*}$ \\
\hline Registered Nurse & 11 & 3 & $27.3 \%$ & 3 & $27.3 \%$ & \\
\hline Other & 6 & 3 & $50.0 \%$ & 2 & $33.3 \%$ & \\
\hline \multicolumn{7}{|l|}{ Years Experience } \\
\hline 1 to 10 years & 58 & 35 & $60.3 \%$ & 21 & $36.2 \%$ & $0.015^{*}$ \\
\hline 11 to 20 years & 32 & 27 & $84.4 \%$ & 18 & $56.3 \%$ & $0.027^{*}$ \\
\hline 21 to 30 years & 6 & 2 & $33.3 \%$ & 0 & $0.0 \%$ & \\
\hline 31 years and over & 3 & 1 & $33.3 \%$ & 1 & $33.3 \%$ & \\
\hline \multicolumn{7}{|l|}{ Work Place } \\
\hline Hospital & 51 & 35 & $68.6 \%$ & 25 & $49.0 \%$ & \\
\hline Health Centre & 45 & 29 & $64.4 \%$ & 15 & $33.3 \%$ & $0.005^{* *}$ \\
\hline Other & 3 & 1 & $33.3 \%$ & 0 & $0.0 \%$ & \\
\hline \multicolumn{7}{|l|}{ Working in Maternity } \\
\hline Yes & 73 & 52 & $71.2 \%$ & 31 & $42.5 \%$ & $0.008 * * *$ \\
\hline No & 26 & 13 & $50.0 \%$ & 9 & $34.6 \%$ & \\
\hline \multicolumn{7}{|l|}{ Work Site } \\
\hline Urban & 70 & 49 & $70.0 \%$ & 36 & $51.4 \%$ & $0.037 *$ \\
\hline Rural & 29 & 16 & $55.2 \%$ & 5 & $17.2 \%$ & $0.005^{* *}$ \\
\hline \multicolumn{7}{|l|}{$\begin{array}{l}\text { Time Since Initial } \\
\text { ALSO Training }\end{array}$} \\
\hline 25-31 Months & 33 & 29 & $87.9 \%$ & 23 & $69.7 \%$ & \\
\hline 13-24 Months & 34 & 24 & $70.6 \%$ & 13 & $38.2 \%$ & \\
\hline 6-12 Months & 31 & 12 & $38.7 \%$ & 4 & $12.9 \%$ & \\
\hline
\end{tabular}

*p-value significant; **p-value very significant; $* * *$ p-value extremely significant 
significant decreases presented in the final column.

A significant decrease in the retest scores was exhibited by those participants working in Health Centre's and Rural Work sites. The time (since ALSO training) category did not demonstrate a loss of skill with time passed with the least decrease occurring with the first groups trained. Fifty-five (55.6\%) participants identified having computer access with no association with passing or failing at the retest.

The sub-set of 15 instructors passed both their initial training test and the retest. Most (13) were trained at the first ALSO course which occurred 31 months prior to the study. The other 2 instructors had their initial ALSO training 15 months previous to the retest. Nine were Trained Midwifes, 4 Physicians, and 2 Nursing Assistants having special obstetrical training. Thirteen worked in urban areas and 2 in rural areas with 11 serving in hospitals and 4 in Health Centres. Eleven of the instructors increased their score on the re-test.

\section{Availability of ALSO recommended equipment and medications}

The ALSO course includes a section which identifies the equipment and supplies necessary to provide emergency obstetrical care. Study participants were asked if they thought their facility had adequate emergency equipment and supplies. Eighty-two (86.6\%) responded that there was adequate equipment/supplies in their facilities with 11 (13.4\%) identifying inadequate equipment/supplies. Participants were also asked if they experienced any difficulty in obtaining obstetrical emergency equipment and/or supplies. Eighty-one (81.8\%) participants responded with 48 (59.3\%) saying they experienced no difficulty while 33 (40.7\%) identified difficulty in obtaining equipment and supplies.

All participants were sent the ALSO recommended equipment/ medication check list and asked to review the adequacy and availability of each item in their facility by checking YES, NO, Do Not Know with return of the listing at their retest. Ninety-one $(91.1 \%)$ returned the equipment listing, with many participants submitting an incomplete listing by selecting not to respond to some of the items. Table 4 presents the responses of those who checked either the YES or NO answer. The number of YES/NO respondents are identified in parenthesis after the named equipment and supplies, with the responses to each item ranging from $61(61.6 \%)$ to 97 (98.0\%).

Magnesium Sulphate (MgSO4) is an important emergency obstetrical medication and was identified to be available within 66 facilities. Study participants said that both $20 \%$ and $50 \% \mathrm{MgSO} 4$ vials were available in 26 facilities, with 20 facilities having only $20 \% \mathrm{MgSO} 4$ and 20 facilities having only $50 \% \mathrm{MgSO} 4$. Of those facilities with MgSO4, 51 (77.3\%) also had Calcium Gluconate available.

\section{Discussion}

A systematic search of the literature identified that the 5 most "commonly cited barriers" to obstetrical emergency care in developing countries included: "inadequate training/skills mix (86\%), drug procurement/logistics problems (65\%), staff shortages (60\%), lack of equipment $(51 \%)$, and low staff motivation (44\%)." identified these same barriers.

Study participants included a population of HCW's who were motivated to improve the emergency obstetrical care they provide as shown by their positive perceptions of the training benefits (95.9\%) and use of the emergency skills (90.8\%). This motivation is also exhibited
Table 4. ALSO practical skills retention.

Participant identification of available equipment and supplies in their facility

\begin{tabular}{|c|c|c|c|c|}
\hline & \multicolumn{4}{|c|}{ Has equipment and supplies } \\
\hline & YES & Percent & NO & Percent \\
\hline \multicolumn{5}{|l|}{ Medications } \\
\hline Oxygen (With Tubing) $(\mathrm{N}=96)$ & 73 & $76.0 \%$ & 23 & $24.0 \%$ \\
\hline IV Fluids (With Tubing) $(\mathrm{N}=96)$ & 85 & $88.5 \%$ & 11 & $11.5 \%$ \\
\hline Pitocin (Oxytocin) (N=97) & 91 & $93.8 \%$ & 6 & $6.2 \%$ \\
\hline Cytotec (Misoprostol) $(\mathrm{N}=97)$ & 85 & $89.5 \%$ & 10 & $10.5 \%$ \\
\hline Magnesium Sulphate $(20 \%)(\mathrm{N}=82)$ & 46 & $56.1 \%$ & 36 & $43.9 \%$ \\
\hline Magnesium Sulphate $(50 \%)(\mathrm{N}=75)$ & 46 & $61.3 \%$ & 29 & $38.7 \%$ \\
\hline Ergometrine/Ergonovine $(\mathrm{N}=82)$ & 30 & $32.6 \%$ & 62 & $67.4 \%$ \\
\hline Calcium Gluconate $(1 \mathrm{Mg}, 10 \%, 10 \mathrm{cc})(\mathrm{N}=90)$ & 58 & $64.4 \%$ & 32 & $35.6 \%$ \\
\hline Nefedipine $(\mathrm{N}=95)$ & 89 & $93.7 \%$ & 6 & $6.3 \%$ \\
\hline \multicolumn{5}{|l|}{ Neonatal Resuscitation Equipment } \\
\hline Ambu Bags $(\mathrm{N}=96)$ & 75 & $78.1 \%$ & 21 & $21.9 \%$ \\
\hline \multicolumn{5}{|l|}{ Infant Mask-Inflatable Cushion } \\
\hline Preterm $(\mathrm{N}=91)$ & 40 & $54.8 \%$ & 33 & $45.2 \%$ \\
\hline Term $(\mathrm{N}=76)$ & 43 & $56.6 \%$ & 33 & $43.4 \%$ \\
\hline Toddler Mask $(\mathrm{N}=73)$ & 32 & $43.8 \%$ & 41 & $56.2 \%$ \\
\hline Laryngoscope (N=91) & 49 & $53.8 \%$ & 42 & $46.2 \%$ \\
\hline Miller Blade "0" $(\mathrm{N}=64)$ & 23 & $35.4 \%$ & 42 & $64.6 \%$ \\
\hline Miller Blade "1" (N=54) & 20 & $37.0 \%$ & 34 & $63.0 \%$ \\
\hline Endotracheal Tube "2.5" (N=84) & 42 & $50.0 \%$ & 42 & $50.0 \%$ \\
\hline Endotracheal Tube "3" (N=52) & 25 & $48.1 \%$ & 27 & $51.9 \%$ \\
\hline Endotracheal Tube "3.5" (N=45) & 23 & $41.8 \%$ & 32 & $58.2 \%$ \\
\hline Delee Suction $(\mathrm{N}=74)$ & 25 & $33.8 \%$ & 49 & $66.2 \%$ \\
\hline \multicolumn{5}{|l|}{ Intrapartum Equipment } \\
\hline Vacuum Delivery VR Omni Cups (N=96) & 75 & $78.1 \%$ & 21 & $21.9 \%$ \\
\hline Pudendal Block (Iowa Trumpet) $(\mathrm{N}=61$ ) & 4 & $6.6 \%$ & 57 & $93.4 \%$ \\
\hline \multicolumn{5}{|l|}{ Maternal Resustation } \\
\hline Adult Ambu Bag (n=89) & 65 & $73.0 \%$ & 24 & $27.0 \%$ \\
\hline Adult Face Mask (cushion bed) $(\mathrm{n}=89$ ) & 57 & $64.0 \%$ & 32 & $36.0 \%$ \\
\hline Adult Endotracheal Tubes $(\mathrm{n}=84)$ & 39 & $46.4 \%$ & 45 & $53.6 \%$ \\
\hline Adult Face Mask (Mouth-to=Mouth) $(\mathrm{n}=80)$ & 28 & $35.0 \%$ & 52 & $65.0 \%$ \\
\hline Suction Catheters $(7.5)(\mathrm{n}=79)$ & 40 & $50.6 \%$ & 39 & $49.4 \%$ \\
\hline Suction Catheters $(8)(n=63)$ & 30 & $47.6 \%$ & 33 & $52.4 \%$ \\
\hline \multicolumn{5}{|l|}{ Incomplete Abortion } \\
\hline MVA Syrange $(\mathrm{n}=83)$ & 57 & $68.7 \%$ & 26 & $31.3 \%$ \\
\hline Cannulae $(7 \mathrm{~mm}-12 \mathrm{~mm})(\mathrm{n}=78)$ & 48 & $61.5 \%$ & 30 & $38.5 \%$ \\
\hline Needle Extender (paracervical block) $(\mathrm{n}=63$ ) & 17 & $27.0 \%$ & 46 & $73.0 \%$ \\
\hline Cervical Dilators $(7-12)(\mathrm{n}=75)$ & 38 & $50.7 \%$ & 37 & $49.3 \%$ \\
\hline
\end{tabular}

by almost half of study participants increasing their test scores from the initial training scores.

The study findings indicate that many of the HCW's thought they maintained their knowledge; however, some were not able to demonstrate the skills required to perform the tasks. The loss of practical skills was confirmed with the ALSO testing failure rates increasing from $34.4 \%$ to $59.6 \%$ on the retest. Many studies indicate that most skills decrease with time. In this study, it would seem that skills could be expected to decrease, because the initial testing was done at the end of the training course when the information was first learned. However, there was no association with time passed and a decrease in skills, with the highest grades occurring in the HCW's who first completed the course. Instead the decrease in skills was primarily associated with the HCW's ability to practice or use the skill, as shown by the skill maintenance of the instructors and by those staff working where there were more opportunities to perform the skills. These study findings support the need to provide ongoing "refresher" training 
to all obstetrical staff for skill maintenance. We believe that there is also a second benefit to refresher courses which can help provide motivation and maintain interest, especially in those facilities where these emergencies occasionally occur.

It is concerning that just over one-third of the trainees failed the initial practical skills testing. Additionally, the primary predictor of failing the study retest was a failing score on the initial test. No associations for this were evident within the study findings. We hypothesize that this finding may be secondary to the individual's incomplete or insufficient knowledge base leading to persistent difficulties in understanding the course lessons. The ALSO program requires that a pretest be given prior to starting the training which was done. However, the ALSO courses proceeded based upon the assumption that the participants had an adequate knowledge base to fully benefit from the training. The focus of this study was to assess the participant's knowledge and skill retention after completing the ALSO course. Therefore, the pretest scores were not included within the study data collected and analyzed. We plan to review the study participant's pretest and compare their scores to the initial course test and retest. Accomplishing this comparison may reveal a participant's readiness to attend the ALSO training with some of these study participants better served by being triaged to an alternate emergency training, such as BLSO or C-BLSO training.

The study findings did reveal some inconsistencies with commonly described clinical activities. The quoted incidence of Shoulder Dystocia is less than $1.0 \%$ of births [25]. Attending at least one delivery with a Shoulder Dystocia was identified by $55.6 \%$ of participants which is greater than expected. The maneuvers used will not harm either the mother or baby and should be continued whenever Shoulder Dystocia may be suspected. Yet, if the occurrence of Shoulder Dystocia is greater than expected, further evaluation is required to identify if this is an increased complication in this population, the result of a conservative practice, or some other cause.

In some facilities, the use of a Vacuum Assisted Deliveries seemed to be more than commonly cited. Additionally, some complications identified seemed higher than anticipated. For instance, 33\% of participants had encountered cephalohematomas with vacuum deliveries; the commonly identified incidence of cephalohematomas is $14-16 \%$ [26]. With adequate training and careful patient selection, a vacuum-assisted delivery can be a valuable tool for the delivery of the women with obstetrical complications and the at-risk fetus. Yet, the potential risks and benefits of a vacuum-assisted delivery must be weighed against the available alternatives, including continued expectant management, oxytocin augmentation, and cesarean delivery. Ongoing monitoring of the use of vacuum extraction for delivery commonly occurs in most obstetrical facilities as part of a quality assurance process. In those facilities where vacuum deliveries occur, a review of each vacuum delivery performed, including indication, should be considered as part of a quality improvement review.

Although extremely rare, instances of overdosing especially with the use of $50 \%$ Magnesium sulfate $\left(\mathrm{MgSO}_{4}\right)$ have been described which have resulted in maternal respiratory depression and arrest [27]. The responses of the participants concerning $\mathrm{MgSO}_{4}$ were so variable that concerns are raised regarding the participant's understanding of $\mathrm{MgSO}_{4}$ dosages and protocols. It is suggested that the available MgSO 4 dosage be evaluated in each facility. Once an accurate assessment is completed, a decision can be made regarding the $\mathrm{MgSO}_{4}$ dosages and protocol. Regardless of the findings, whenever $\mathrm{MgSO}_{4}$ is available, it is essential that Calcium Gluconate also be available if maternal respiratory complications occur.

Over $85 \%$ of study participants identified having adequate equipment/supplies with $60 \%$ of those responding saying they had no difficulty in obtaining equipment and supplies. However, this could not be confirmed in the equipment lists submitted by the study participants. When the ALSO course was begun, funds were available to provide the recommended equipment and supplies to some, but not all, of the facilities. However, a process was put into place to facilitate the procurement and to restock emergency equipment and supplies. The authors have encouraged the staff to obtain emergency equipment and supplies and to maintain them within each facility's obstetrical care area. Protocols have been made available to regularly check the equipment/supplies, and ascertain that the equipment and supplies are available, maintained, and replaced. Yet, following these recommendations has been inconsistent.

\section{Limitations}

This study addressed a small sampling of HCW'S who voluntarily attended a special emergency obstetrical training course in Cameroon. Therefore, the findings may or may not be typical of or generalizable to other HCWs or obstetrical units in Cameroon.

All ALSO course attendees came to the training on a voluntary bases, and it is probable that they were motivated to attend by their special interest in emergency obstetrical care, as indicated by the number of participants whose scores increased on the retest. Therefore, these study participants may be a biased sampling secondary to their interest in improving their knowledge and skills. It is not known if the same interest in EmOC would be shown by other HCWs in Cameroon.

Every effort was made to encourage ALSO trainees to participate in this study. Yet, it was hoped that more than 99 trainees would participate. Concerns were raised that this small number of study participants may bias the findings and not be reflective of the population of HCW's attending ALSO courses. On review, this number of study participants would give a confidence level of $90 \%$ with a $5 \%$ margin of error. Therefore, we believe that the number of study participants is acceptable and that the findings do reflect the true values of the total ALSO course attendees.

\section{Recommendations}

This study has shown that ongoing "refresher" courses are necessary to maintain the quality of obstetrical emergency care. Dedicated and strong leadership is required to maintain staff motivation and interest to address the " 3 rd Delay" barrier. It is recommended that the program be continued under the ALSO Program Manager with the institution of an Advisory Board consisting of ALSO Instructors and Obstetrical Head Nurses. This Advisory Board should meet 1-2 times a year to establish program guidelines (i.e. selecting appropriate training for participants, duration between refresher courses, number of yearly trainings, and periodic auditing of the management of EmOC at each facility) and to discuss the EmOC and a way forward to cope with any identified challenges.

The ALSO Program cannot be successful without the full investment of each facilities' obstetrical staff. Consideration should be given to monitoring the capability of each facility to provide EmOC consistent with the level of care of the facility. This could include onsite supervisory visits by the Program Manager, ALSO instructors, and Obstetrical Head Nurses. In addition, each facility could submit 
a simple self-assessment of their emergency care capability yearly for Advisory Board review. Finally, weekly case presentations of all obstetrical emergency cases should be held in labor and delivery units by the head nurses and/or ALSO instructors to enable the staff to learn from each case and improve their management. The final goal would be that any staff providing obstetrical care would have EmOC training appropriate to their capabilities and work environment.

The 2006 to 2014 CBCHS Activity Reports have identified that 148 women died while in maternity care at CBCHS facilities; this averages to 1-2 maternal deaths occurring monthly in CBCHS facilities. This number of deaths is not acceptable. Yet, no data has been gathered as to why these deaths are occurring, and if, or how, these deaths can be prevented. It is recommended that a system of Maternal Mortality Reviews be developed to identify the causes of and contributors to each Maternal Death with the findings presented in a yearly report to CBCHS administration, obstetrical care providers, and other interested partners. This report would be very helpful to identify activities which could be implemented to avoid preventable deaths and develop community educational efforts.

\section{Authorship and contributorship}

Each author contributed to the study conception, design, analysis, and interpretation of the data. Each author participated in the writing the manuscript, reviewing, and revising the manuscript. Each author has approved the manuscript for submission for publication.

\section{Acknowledgement}

The following Supervisors and ALSO Instructors/Research Assistants are recognized for their assistance which made this study possible: Prof. Peter Maina Gatongi and Mrs. Mbai Isbella (Supervisors); Ms. Ndi Maria, Mr. Monjuh Anthony, Ms. Kenchi Hope Banlon, Ms. Pheungeh Beniolite, Ms. Nga Priscilla, Dr. Atta Constance Ndum, Ms. Tih Emmaculate, Ms. Tangwa Doris, and Ms. Yuniwoh Delphine (Research Assistants). These capable individuals are recognized for their motivation, enthusiasm, and efforts to introduce and maintain EmOC in obstetrical facilities.

\section{Funding}

A grant from private donors supported this study. No salary or funds were received by the authors, research assistants, or participants for their contributions or study participation.

\section{Competing interest}

The authors have no competing interests.

\section{References}

1. World Health Organization (2015). Maternal mortality - Fact Sheet. WHO Media centre. November 2015. http://www.who.int/mediacentre/factsheets/fs348/en/

2. Say L, Chou D, Gemmill A, Tunçalp Ö, Moller AB, et al. (2014) Global Causes of Maternal Death: A WHO Systematic Analysis. Lancet Global Health 2: e323-e333.

3. World Health Organization UNICEF, UNFPA, World Bank Group and the United Nations Population Division (2015). Trends in Maternal Mortality: 1990 to 2015 Estimates by WHO, UNICEF, UNFPA, World Bank Group and the United Nations Population Division. November 2015. http://www.who.int/reproductivehealth/ publications/monitoring/maternal-mortality-2015/en/

4. Alkema L, Chou D, Hogan d, Zang S, Moller AB, et al. (2015) Global, regional, and national levels and trends in maternal mortality between 1990 and 2015, with scenariobased projections to 2010: a systematic analysis by the UN Maternal Mortality Estimation Inter-Agency Group. The Lancet. November 2015. http://www.thelancet. $\mathrm{com} / \mathrm{pb} /$ assets/raw/Lancet/pdfs/S0140673615008387.pdf
5. Lalsser R, Managwa S, Libaha E, Kimweri M, Bedwell C (2015) 'Phase 3 delay' threats to laboring women. African Journal of Midwifery and Women's Health 9: 35-41.

6. Echoka E, Makokha A, Dubourg D, Kombe Y, Nyadieka N, Byskov J (2014) Barriers to emergency obstetric care services: accounts of survivors of life threatening obstetric complications in Malindi District, Kenya. Pan African Med Journal. [Crossref]

7. Knight HE, Self A, Kennedy SH (2013) Why Are Women Dying When They Reach Hospital on Time? A Systematic Review of the 'Third Delay'. PLOS one 8: e63846.

8. Sorensen B, Nielsen B, Rasch V, Elass P (2011) User and provider perspectives on emergency obstetric care in a Tanzanian rural setting: A qualitative analysis of the three delays model in a field study. Afr J Reprod Health 15: 117-130. [Crossref]

9. Harvey S, Blandon Y, McCaw-Binns, Sandino I, Urbina C, et al. (2007) Are skilled birth attendants really skilled? A measurement method, some disturbing results and a potential way forward. Bull World Health Organ 85: 783-790. [Crossref]

10. Pearson L, Larsson M, Fauveau V, Standley J (2006) Opportunities for Africa's newborns: Practical data, policy and programmatic support for newborn care in AfricaChapter 3, Partnership for Maternal, Newborn \& Child Health (PMNCH), Publisher: WHO on behalf of The Partnership for Maternal Newborn and Child Health, 2006. www.who.int/pmnch/media/publications/aonsectionIII_3.pdf

11. World Health Organization (2005) The world health report 2005 - make every mother and child count. World Health Organization. http://www.who.int/reproductivehealth/ publications/maternal_perinatal_health/9241562900/en/

12. United Nations Population Fund (UNFPA) Cameroun (2014) Government of Cameroon Launches Multisectoral Program to Reduce Maternal \& Child Mortality, UNFPA Cameroun. http://countryoffice.unfpa.org/cameroun/2014/05/16/9743/ government_of_cameroon_launches_multisectoral_program to_reduce_maternal amp_child_mortality/

13. IndexMundi (2015) Country Comparison - Maternal mortality rate rank chart. http:// www.indexmundi.com $/ \mathrm{g} / \mathrm{r} \cdot \mathrm{aspx}$ ? $\mathrm{c}=\mathrm{cm} \& \mathrm{v}=2223$

14. Mbuagbaw L, Obadeyi B, Mbuagbaw J, Doh AS (2009) Improving Maternal Health and Meeting Targets of the Fifth Millennium Development Goal in Cameroon: A framework for action. Clinics in Mother and Child Health. http://www.ajol.info/index. $\mathrm{php} / \mathrm{cmch} /$ article/viewFile/54335/42854

15. Leina CY (2011) Cameroon Loses Ground on Maternal Health Goal. Women's eNews June 4, 2011. http://womensenews.org/2011/06/cameroon-loses-ground-maternalhealth-goal/

16. American Academy of Family Practice (2015) Advanced Life Support in Obstetrics $\left(\mathrm{ALSO}^{\circledR}\right)$. AAFP ALSO website. 2015. http://www.aafp.org/cme/cme-topic/maternity/ also.html

17. American Academy of Family Practice (2015) $\mathrm{ALSO}^{\circledR}$ International and Global ALSO $^{\circledR}$. AAFP ALSO website. http://www.aafp.org/cme/cme-topic/maternity/also/ courses/international.html

18. Dresang L, Gonzalez M, Beasley J, Bustillo M, Damos J, et al. (2015) The impact of Advanced Life Support (ALSO) training in low-resource countries. Int J Gynaecol Obstet 131: 209-215. [Crossref]

19. Evensen A, Dresang L (2012) "ALSO, BLSO, C-BLSO and Global ALSO: Obstetric simulation and skills training for a global audience." AAFP Family Medicine Global Health Workshop. Minneapolis, MN September 2012. http://www.fmdrl.org/index. $\mathrm{cfm}$ ? event $=\mathrm{c}$.accessResource $\&$ rid $=4088$

20. Cameroon Baptist Convention Health Service (CBCHS) (2015) Cameroon Baptist Convention Health Services Activity Report - 2014, Reports and Publications, www. cbchealthservices.org.

21. Mirkuzie A, Sisay M, Bedane M (2014) Standard basic emergency obstetrical and neonatal care training in Addis Ababa; trainees reaction and knowledge acquisition. BMC Medical Education. http://www.biomedcentral.com

22. Tuyisenge L, Kyamanya P, Van Steirteghem S, Becker M, English M, et al. (2014) Knowledge and skills retention following Emergency Triage, Assessment and Treatment plus Admission course for final year medical students in Rwanda: a longitudinal cohort study. Arch Dis Child 99: 993-997. [Crossref]

23. Homaifar N, Mwesigye D, Tchwenko S, Worjoloh A, Joharifard S, et al. (2013) Emergency obstetrics knowledge and practical skills retention among medical students in Rwanda following a short training course. Int J Gynaecol Obstet 120: 195-199. [Crossref]

24. Yang CW, Yen ZS, McGowan JE, Chen HC, Mancini ME, et al. (2012) A systematic review of retention of adult advanced life support knowledge and skills in healthcare providers. Resuscitation 83: 1055-1060. [Crossref] 
Bongban NG (2016) Emergency obstetrics knowledge and practical skills retention among hospital and clinic staff following advanced life support obstetrical training in Cameroon, Africa

25. (RCOG) Royal College of Obstetricians and Gynaecologists (2012) Shoulder Dystocia: Green-top Guideline No. 42.

26. Unzila A, Norwitz, E (2009), Vacuum-Assisted Vaginal Delivery. Rev Obstet Gynecol 2: 5-17. [Crossref]
27. Smith J, Lowe R, Fullerton J, Currie S, Harris L, et al. (2013) An Integrative Review of the Side Effects Related to the Use of Magnesium Sulfate for Pre-eclampsia and Eclampsia. BioMed Central Pregnancy \& Childbirth. http://www.medscape.com/ viewarticle/803082

Copyright: (C2016 Bongban NG. This is an open-access article distributed under the terms of the Creative Commons Attribution License, which permits unrestricted use, distribution, and reproduction in any medium, provided the original author and source are credited. 